independent of local politics, even though of a different kind.

Closer examination of the Green Paper will raise many matters of detail for comment or criticism. One of the most obvious omissions is any arrangement for bringing the occupational health services into the N.H.S. fold. There will be criticism too of the abolition of the boards of governors of teaching hospitals and the implied submergence of these hospitals in the main stream of hospital provision. The needs of undergraduate teaching could partly be met by making greater use of district hospitals, and teaching hospitals have a general as well as a special contribution to make towards the provision of medical services. Nevertheless, their relationship with universities should be strengthened.

The most vehement criticism of the Minister's administrative scheme will come from the medical officers of health, who are affected more than any other doctors. The Green Paper acknowledges this by deploying as persuasively as it can the arguments in favour of the area boards taking over the community health services. It sees medical officers of health as officers of the boards, being able to extend their role as community physicians-" specialists in community medicine." Meanwhile the Seebohm Committee recommends, irrespective of what changes may come about as a result of the report of the Royal Commission on Local Government, that the heads of new social service departments should be people professionally qualified in social work. The transfer to lay staff-if that is what it means-of medical and social functions now carried out by doctors raises ques- tions of principle which are of concern to all doctors, ${ }^{5}$ and this issue must be seen as one which goes far beyond simply depriving medical officers of a function.

The Green Paper is to be welcomed as an admirably brief basis for the discussion of overdue reforms in the administration of the Health Service. Much of what is proposed is in line with current thought, and, brisk though the debate is bound to be on many matters-and not only matters of detail -it is possible to see emerging an administrative framework which could satisfactorily accommodate the evolving patterns of medical practice. But those who want to see a greater trend towards a real decentralization of responsibility for the provision of medical services will be disappointed. The Minister of Health made it clear last year that his review would not take into account any possible changes in methods of financing the Health Services. Perhaps he has that in mind for his next review. It is to be hoped so, because real reforms in the N.H.S. in the direction of devolution of responsibility depend as much on financial changes as on administrative ones, but any proposals would need the most careful study.

\footnotetext{
- A Review of the Medical Services in Great Britain, 1962. London.

2 Brit. med. 3. Suppl., 1968, 1, 19.

- The Administrative Structure of the Medical and Related Services in England and $W$ ales, 1968. H.M.S.O., London. Price 3s. 6d. net.

- Report of the Committee on the Local Authority and Allied Personal Social Services, 1968, Cmnd. 3703. H.M.S.O., London. Price 31 s. net.

- Brit. med. 7., 1966, 2. 1217.
}

\section{Encephalopathy from Penicillin}

Encephalopathy may occasionally follow the intravenous injection of high doses of penicillin in a patient with renal failure. $^{1}$ In such cases the efficient clearance of penicillin is probably hampered, so that high concentrations accumulate in the blood and hence in the cerebrospinal fluid.

The importance of the concentration of penicillin in the cerebrospinal fluid has been shown by $\mathrm{H}$. Smith, P. I. Lerner, and L. Weinstein, ${ }^{2}$ for they found that, even when high doses were given, if the concentration in the C.S.F. did not exceed 10 units per ml. little danger of fits resulted. They considered it unwise to exceed this figure. Another aspect of this problem has recently been reported by $K$. B. Seamans, P. Gloor, A. R. C. Dobell, and J. D. Wyant. ${ }^{3}$ In early 1965 four patients undergoing open heart surgery with cardiopulmonary bypass at the Royal Victoria Hospital, Montreal, developed status epilepticus and coma in the immediate postoperative period, and three of them died. Each had received large doses of sodium penicillin intravenously over a period of eight hours before, during, and after the bypass procedure, with the aim of preventing bacterial endocarditis or infection at the site of the valve prosthesis. None of these patients had azotaemia. Penicillin had not been used in this manner in the unit before January 1965 and was not given after March, and there were no previous or subsequent cases. The authors then carried out experiments on dogs and found that, if large amounts of penicillin were given intravenously alone, no fits or electroencephalographic changes were observed, but out of eight animals in which this was combined with a full bypass operation seven developed fits. None of the five animals having full bypass but no penicillin developed fits. It is suggested that a breakdown, as yet unexplained, of the blood-brain barrier occurs after cardiopulmonary bypass, which does not appear to be related either to changes in the blood $\mathrm{pH}$ or to haemolysis, and there has been no convincing evidence of air embolism, particulate embolism, or thrombosis of vessels. These authors in another paper do suggest, however, that small aggregates of material such as fat globules may become temporarily trapped in the cerebral capillaries and produce local deficiency in the bloodbrain barrier, which may allow passage of abnormal quantities of penicillin."

Whether this is the explanation or not, these cases are another example of the potential neurotcxic effects of penicillin when allowed to come in contact with the brain in high concentration. There is also the possibility that during cardiopulmonary bypass operations other drugs usually given with safety may more readily be able to exert direct influence on the brain and produce unexpected, unfamiliar, and perhaps undesirable effects.

\footnotetext{
1 Bloomer, H. A., Barton, L. J., and Maddock, R. K., F. Amer. med. Ass., 1967, 200, 121.

2 Smith, H., Lerner, P. I., and Weinstein, L., Arch. intern. Med., 1967, $120,47$.

seamans, K. B., Gloor, P.; Dobell, A. R. C., and Wyant, J. D., New Engl. Ұ. Med., 1968, 278, 861.

- Dobell, A. R. C., Wyant, J. D., Seamans, K. B., and Gloor, P., F. thorac. cardiovasc. Surg., 1966, 52, 469.
} 